\title{
INCORPORATION OF UNIVERSAL PREVENTION CURRICULUM INTO ESTABLISHED ACADEMIC DEGREE STUDY PROGRAMME: QUALITATIVE PROCESS EVALUATION
}

\author{
Michal Miovský1, Anna Vondrová1, Roman Gabrhelík¹, Zili Sloboda², Jiři Libra', Amalie Lososová1 \\ 'Department of Addictology, First Faculty of Medicine, Charles University and General University Hospital in Prague, Prague, Czech Republic \\ ${ }^{2}$ Applied Prevention Science International, Ontario, Ohio, USA
}

\section{SUMMARY}

Objective: Comprehensive bachelor's, master's, and doctorate-level curricula of Addiction Studies (Addictology) were developed and implemented at Charles University (First Faculty of Medicine) between 2003 and 2012. This Prague model combines three evidence-based approaches to addressing substance use - prevention, treatment, and public health - into a balanced professionalised discipline. Graduates from this programme are licensed by the State Authority as addictology, a regulated profession in the Czech Republic. Professionals with these degrees are recognised as healthcare professionals, can perform directly in the field and can be contracted by health insurance companies. In 2016, it was decided to integrate the Universal Prevention Curriculum (UPC) into these programmes of study. The UPC was developed by a group of prevention researchers from the United States. This article describes the technical steps involved when adapting the UPC into an established university degree programme. We describe the requirements needed for successful implementation and reaccreditation. Finally, we examine both barriers and enhancers of the adoption of UPC as a university programme.

Methods: A qualitative process evaluation study was conducted on the activities carried out in 2017-2018, demarcated by a successful university accreditation of the new curricula combining the original Prague model and the UPC curriculum. Field records, observation methods, official documents, curricular documents, syllabuses, content analysis, and thematic analysis were used for this process.

Results: We identified three clusters of issues and challenges during the adaptation and implementation process: technical (developing a new credit scheme, adopting new terminology using local and culture-specific examples, and cancelling, establishing, and/or fusing particular courses, identifying some critical issues for any practical implementation of the UPC); teaching staff-related (team work, involving motivated and qualified staff for moving from a national to an international perspective); and content and contextual (the conflict between different theoretical perspectives such as public health vs. mental health and drug use prevention vs. risk behaviour prevention).

Conclusion: The adaptation of the UPC had a significant impact on study profiles and competencies. Such an implementation necessarily requires a team of staff members with sufficient capacities to be able to coordinate the process, facilitating each step and supervising it. The current adaptation of the UPC involved specific merging procedures to fit in with existing courses and emphasising an international perspective. This process opened a national discussion about the implementation of the UPC in the system of life-long education programmes and training. Beginning in September 2019, when the first group of students will attend this new model of Addictology studies, we will continue our evaluation of the implementation process and the factors that played a role in either hindering or supporting the implementation. The findings from this evaluation will be used to make adjustments to the curriculum.

Key words: academic degree study programmes, specialised addiction programmes, prevention, curriculum, adaptation, implementation process

Address for correspondence: M. Miovský, Charles University and General University Hospital in Prague, First Faculty of Medicine, Department of Addictology, Apolinářská 4, 12800 Prague 2, Czech Republic. E-mail: michal.miovsky@lf1.cuni.cz

https://doi.org/10.21101/cejph.a5952

\section{INTRODUCTION}

Within the last two decades, we have witnessed a new trend of establishing specialised academic degree programmes in addictions focused on substance use prevention, treatment, or harm reduction or mixing these perspectives into one uniform programme. In a recent study, a large number of addiction study programmes were identified around the world, specifically 34 programmes in Europe, 392 programmes in the USA, and 58 programmes in other regions around the globe $(1,2)$. However, most of these university degree programmes have been developed under varying conditions and with varying foundations and have diverse structures. There is a great diversity of addiction studies programmes around the world. Some programmes are more comprehensive in perspective as they combine topics from the areas of prevention, treatment, harm reduction, recovery, 
and/or criminal justice. Others are specifically focused on one certain field of interest. In spite of the extensive heterogeneity, it is possible to observe some common characteristics in the programmes and similar experiences during their development, implementation, and operation. When concentrating on prevention programmes in the addiction field, we can assume that most programmes integrate this theme into the curriculum (courses such as Evidence-based Practice Applied to Prevention and Treatment; Prevention of Drug Use and Abuse; Epidemiology, Prevention, and Treatment Research; Contemporary Advances in Addiction Research, Policy, Prevention, and Practice; Prevention; Prevention Issues in Addiction Studies, etc.) but only a few are focused on prevention, as shown by their titles, such as a Croatian programme "Prevention Science and Disability Studies" (3), or "Health and Social Development (Youth Addiction Support)" from the Unitec Institute of Technology in New Zealand. In our review, we found 15 programmes focused on prevention in the addiction field in the USA (out of a total of 392 identified programmes) (2), according to pre-defined key words (which did not include the word "prevention" specifically), i.e. "Prevention and Addiction Studies" at Boise State University in Idaho, "Addiction Prevention" at the University of Nevada in Las Vegas, and "Prevention Science" at the University of Oklahoma.

In our review of the scientific literature, we found only a few studies presenting the results of any type of evaluation of these academic programmes $(4,5)$. It is worth noting that studies focused on emerging or already established study programmes are relatively common. On the other hand, we see a lack of activities and studies focused on study programmes that were terminated or were struggling for survival are over-represented. The issue of evaluation is a very important aspect that can provide a better understanding of the entire process of developing new universitybased study programmes specialising in addiction (for example in Germany) (6).

Evaluation studies of these programmes provide useful information to education providers but also to the labour market. Employers as well as professional groups and the general public will better understand graduates' profiles, their competencies, and their role in the labour market. There is a synergy between university education and the labour market. The needs of the labour market generate a demand for specifically trained professionals. But the recognition of a profession for specific knowledge and competencies also has an impact on the labour market not only in guiding who is to be hired but also in creating new jobs. This simple rule stimulates the emergence of evidence-based (i.e. evaluated) study programmes (7).

Experience clearly shows that the development of highly specialised university-based educational programmes, for example specifically in prevention, also requires the revision of the addiction field as a whole and of the field-related institutional infrastructure (8). The operational institutional infrastructure comprises not only teachers and trainers, but also research institutions, specialised libraries, journals, and professional associations.

Moreover, the creation of national institutional infrastructures (which interconnect professional services, scientific, academic, and financial frameworks) may be considered the key strategy in pursuing a higher quality and gradual professionalisation of prevention work and workforce at the local, national, and international levels (9). We are witnessing the emergence of international networks, such as the US Society for Prevention Research (SPR) and the European Society for Prevention Research (EUSPR), or the International Consortium of Universities on Drug Demand Reduction (ICUDDR). One of the aims of the ICUDDR, which was established in 2016, is to support closer collaboration and communication between universities across the globe in order to share experience and recommendations as to how to implement addiction studies programmes under different conditions. For these purposes they use the Universal Prevention Curriculum (UPC) and Universal Treatment Curriculum (UTC). The ICUDDR, in particular, represents an important link supporting the development of collaboration between organisations such as the SPR and the EUSPR and the academic sphere, providers of prevention services and interventions, and prevention practitioners.

The entire process of preparing, establishing, and operating university degree study programmes in addictions must be understood in the wider context of the development of quality prevention-related policy. In the last two decades, this multifaceted phenomenon has played a significant role in shaping discourse across professional groups. Besides being a subject of lively debates within international and national professional associations, it led to the formulation of the first international and national quality standards for substance use prevention (10-12). For example, the Czech Republic began to address the issue of quality standards as part of a certification process as part of the European Commission-funded Phare "Twining project 2000". In addition to standard governing methods and interventions, including the ways of providing them, the Czech Republic also embarked on addressing a quality standard pertaining to the training of prevention professionals, i.e. the notion of quality derived from prevention practitioners. This gave rise to a working tool (standard) which can be used to test professional qualifications needed for prevention work, irrespective of one's original professional background (education, psychology, medicine, etc.). The development and the nationwide implementation of the quality standards in prevention was closely related and aligned with the development of the university addiction training curriculum, which later became known as the Prague comprehensive model of addiction studies $(13,14)$.

\section{Prague Model of Addiction Studies and Universal Prevention Curriculum}

The Prague comprehensive model of addiction studies was built on a generic view of the addiction specialist as a professional who is competent and ready to work in the prevention sphere as well as in treatment or other addiction service systems (15). The original idea, development, and the process of establishing an academic degree study programme specialising in addiction has been published elsewhere $(13,14)$. During the period 2002-2004, the core concept of the bachelor's (BA) study programme (in addictology) and the national accreditation were developed. The bachelor's (BA) programme opened in September 2005. It was designed as a very practical, clinically-oriented programme for producing well-trained professionals for clinical practice who can provide a wide range of basic therapeutic and preventive interventions. Graduates (called addictologists) received a special licence as health professionals (like nurses, clinical psychologists, 
etc.) and had a very clear job description and fixed position in the healthcare system and prevention field. In September 2008, a master's (MA) study programme was opened. The MA programme was designed in continuity with the BA programme in terms of its clinical profile but put more stress on having a theoretical background (less practical training and more theory) and a wider mental health and public health approach. The MA programme also accepted other professionals (psychologists, social workers, etc.). In September 2012, a doctoral (PhD) study programme with a focus on theory and practice in addictions and capacity building in Addiction Science was opened. The comprehensive educational programme operating at all three academic degree levels expanded rapidly and the current bachelor's, master's, and doctoral-level programmes now train more than 250 students a year and are recognised as the Prague comprehensive model of addiction studies (14).

The genesis of addictology was greatly facilitated by the efforts of a number of academic, governmental, EU, and non-governmental organisations, important policy changes, and widespread support among addiction services. Addictology's transdisciplinary nature - uniting various disciplines that elsewhere often compete - is key to its current status in the Czech Republic and to a comprehensive understanding of the complex and dynamic risk environment of substance use and addictive behaviours.

\section{Universal Prevention Curriculum}

The Universal Prevention Curriculum (UPC) was created by a team of highly qualified scientists and prevention professionals in collaboration with the work group coordinator Zili Sloboda and has been repeatedly evaluated and tested. It integrates all the key prevention issues including: a general introduction to the physiology and pharmacology of addictions; a general introduction to preventive science and evidence-based approaches; prevention theory and background; evidence-based preventive interventions and policies; and preventive research, monitoring, and evaluation. Manuals for students and teachers have been developed along with additional readings, examples, instructions, presentations for trainers and teachers, etc. The UPC has two series (Tables 1 and 2): for implementers and for coordinators.

\section{Merger of the Prague Model and UPC}

The prevention strand of the original university curriculum grew in significance in the course of time, with the adaptation and implementation of the UPC becoming a crucial moment. This step, however, involved essential issues such as integrating the first international comprehensive prevention curriculum into the existing academic study programme which had evolved over several years and followed a curriculum of its own. In this context, the entire adaptation and implementation process was conceived of as comprising preparatory work, work

Table 1. Universal prevention curricula: implementer series

\begin{tabular}{|l|l|l|}
\hline Track & Title & Hours include training and practica \\
\hline Track 1 & Introduction to Prevention Science & 40 hours \\
\hline Track 3 & Physiology and Pharmacology for Prevention Specialists & 24 hours \\
\hline Track 4 & Monitoring and Evaluation of Prevention Interventions and Policies & 40 hours \\
\hline Track 5 & Family-Based Prevention Interventions & 32 hours \\
\hline Track 6 & School-Based Prevention Interventions & 40 hours \\
\hline Track 7 & Workplace-Based Prevention Interventions & 24 hours \\
\hline Track 8 & Environment-Based Prevention Interventions & 24 hours \\
\hline Track 9 & Media-Based Prevention Interventions & 24 hours \\
\hline Track 10 & Community-Based Prevention Implementation Systems & 40 hours \\
\hline & Total & 288 hours \\
\hline
\end{tabular}

Table 2. Universal prevention curricula: co-ordinator series

\begin{tabular}{|l|l|l|}
\hline Track & Title & Hours include training and practica \\
\hline Track 1 & Introduction to Prevention Science & 42 hours \\
\hline Track 3 & Monitoring and Evaluation of Prevention Interventions and Policies & 90 hours \\
\hline Track 4 & Family-Based Prevention Interventions & 120 hours \\
\hline Track 5 & School-Based Prevention Interventions & 140 hours \\
\hline Track 6 & Workplace-Based Prevention Interventions & 130 hours \\
\hline Track 7 & Environment-Based Prevention Interventions & 100 hours \\
\hline Track 8 & Media-Based Prevention Interventions & 130 hours \\
\hline Track 9 & Community-Based Prevention Implementation Systems & 130 hours \\
\hline & Total & 882 hours \\
\hline
\end{tabular}


with an academic team, accreditation according to the national standards and requirements equalling a programme operating for students (not Life-long Education Trainings); realistic training/practical (internship) components and matching of learning outcomes with the "real world" labour market and needs of employers or potential employers; and linking the study programme within the existing institutional prevention infrastructure (national societies, employers, journals, policymakers, legislation, etc.).

In order to accomplish this transition, it was decided to conduct a qualitative study of the process. The aim of this study was to examine the determinants of success so as to contribute to a broader discussion about the transferability and adaptation of curricula in terms of cultural, legislative, and clinical perspectives in order to support the development of the addiction field. Thus, the objectives of the study were to describe all the particular technical steps involved in integrating the UPC curriculum into an existing university study programme; analyse the requirements for its successful implementation and re-accreditation; and provide better evidence of the phenomena that interfered with or enhanced this process.

\section{Methodological Framework and Database}

A qualitative evaluation study of the process was inspired by the WHO series for the evaluation of drug services and interventions $(16,17)$. The data sources were field records (team meetings, working groups, etc.), observation methods, official university documents (rules, norms), and curricular documents (accreditation forms, additional documents following the accreditation form etc.), syllabuses, etc. The data coding was conducted according to the principles of open coding by Strauss and Corbin (18) and analysed through content analysis and thematic analysis inspired by Miles and Huberman (19). The first part of the study (presented in this paper) was delineated by the successful official accreditation of new curricula combining the original Prague model and the UPC. For the evaluation we used a structural perspective and went through the implementation process step by step with full respect to both models. The second part (planned evaluation study) of the implementation and evaluation will start in September 2019 with the new academic year (Phase 3: Re-assessment phase and Phase 4: Finalisation), when we will test the new comprehensive curricula on the first group of students (70 students in BA programme and 25 students in MA programme). The first phase of the study presented here was based on an implementation evaluation conducted in 2017-2018 that was divided into three phases:

Phase 1: Preparatory phase

2017: Developing collaboration with US colleagues (group under the umbrella of the ICUDDR, etc.), a technical period, and planning the project and its details.

Phase 2: Analytical phase

2017-18: Content analysis, comparative, study and inserting the UPC curriculum into the Prague model of addiction studies. Phase 3: Implementation phase

2018: Accreditation of the new models of BA and MA programmes and adaptation of the legislation - the position of an "addiction specialist" in the Czech Republic as a regulated health profession.

\section{RESULTS}

\section{Professional Competencies}

It was necessary to combine the coordinator and implementer series of the UPC because of the defined professional competencies of addictologists in the Czech legislation (14). The Czech legislation (Decree No. 55/2011 Coll.) names seven areas in which an addictologist (a graduate of the BA programme) should be competent and able to provide these services (without the supervision and indication of a medical doctor). Because of the treatment character of the addictologist's profile we are talking about these areas: diagnostics, non-invasive collection of biological material, and providing individual and family support therapy. Other areas are specifically bound to prevention. Here we are talking about the establishment of a primary prevention programme including early diagnosis or needs assessment and the selection of intervention programmes, screening to identify persons at risk of addiction, educating other healthcare workers in this area, and providing counselling in this area. It is obvious that these competencies are very practical and the aim of the BA study programme is to equip the graduate with the skills needed for fieldwork.

Therefore, a more intensive focus was put on the coordinator series (for practically oriented professionals in the prevention field in the BA programme). A graduate of the bachelor's programme understands the goals and procedures of the primary prevention of addictive behaviour and the emergence and development of behavioural addictions, and knows and can implement basic skills in preventive educational work. The graduate is able to independently apply, adapt, implement, and evaluate preventive interventions at the level of universal, selective, and indicated prevention, including basic counselling (graduate profile). The focus of the courses was originally (before the implementation of the UPC) targeted towards children and especially school-based prevention programmes. The new form (after the implementation of the UPC) emphasises all the contexts important for effective prevention, i.e. not only the school environment, but also the family and workplace, which are connected to fieldwork.

For the MA programme we have emphasised the Implementer UPC series. At this degree level we expect the graduate to understand the goals and procedures of the primary prevention of addictive behaviour and the emergence and development of behavioural addictions, which are oriented towards work in a broader context - environmental prevention, prevention in the media, prevention at the community level - and understand procedures for evaluating the effectiveness of preventive interventions and policies (graduate profile). Compared to the BA level, the MA graduate should be oriented in the system in terms of public health and be connected to other public health courses. Before the UPC was implemented, the accreditation file presenting the study programme highlighted nine specific areas and a focus on related courses. In these areas, prevention was not represented except in the area of school-based prevention.

The major shift was represented by a more universal profile and more general definition of competencies with the emphasis on prevention both as related to all other areas (a component of other courses) and as a separate area needing proper designated hours and specific prevention courses according to the content and focus of all the UPC tracks. As we re-defined the output com- 
petencies of the graduates, we also needed to change the learning outcomes so as to be able to teach the students the appropriate contents. It is important here to explain the major differences in the final competencies required of the bachelor's and master's graduates. The difference is in the formal qualification (as the BA is a licensed healthcare professional), and so the BA graduates gain clinically oriented knowledge as we expect them to do practical preventive work in the field. The master's graduates are more oriented towards the broader context, the application of prevention/treatment to other disciplines, and to evaluation. It was necessary to insert the changes (evoked by the implementation of the UPC) in the description of professional competences at the BA and MA levels into the legislation and receive the final approval of all the relevant university bodies (academic senate, scientific board, etc.) and all the regulatory bodies (Ministry of Education and Ministry of Health).

\section{Redefinition of Learning Outcomes}

Learning outcomes (knowledge-skills-competencies) play an important role in the European accreditation rules for universities $(20,21)$. Briefly, this qualification framework was implemented in the Czech Republic in 2009 and since then, the goal has been to implement it for each study field. As mentioned above, this process is important so as to recognise the qualifications of graduates across Europe and it is also a tool for creating a system of clearly formulated and understandable learning outcomes. We had to redefine the learning outcomes for both levels/programmes (BA and MA) according to the new profile of competencies of graduate professionals. In general, each subject/course has two to eight learning outcomes describing knowledge and skills. The third component is called "competencies" and this category refers to acquired general competencies not necessarily related to the given field, for example the skill of cooperating in a team. Before the implementation of the UPC, the study programmes had very few learning outcomes defined specifically for the area of prevention. On the BA level the outcomes were mostly formulated in the category of knowledge. As mentioned above, prevention issues (before the implementation of the UPC) were covered in general courses that focused on different issues rather than specifically on prevention. As an example, the course Tobacco Addiction: Prevention and Treatment works equally with the topics of treatment and prevention related to tobacco addiction. There is a clear gradation in the BA and MA levels; we expect a process of the development of the students, and so the courses are connected progressively. The learning outcomes reflect this progress.

Practically, in the BA programme four new UPC prevention courses have been implemented: Introduction to Prevention of Risk Behaviours, School-Based Prevention, Family-Based Prevention, and Workplace-Based Prevention (Table 3). In the MA programme, there are also four new UPC courses: EnvironmentBased Prevention and Public Health Interventions, Media-Based Prevention and Information and Communication Technologies (ICT), Community-Based Prevention Implementation Systems, and Monitoring and Evaluation of Prevention Interventions and Policies (Table 4). The UPC trainer manuals play a critical role as they provide their own (original) learning outcomes (also learning objectives) for each course and curriculum and help in the process of redefining learning outcomes. They also contain all the key concepts, terminology, definitions, etc., so there is no need for a university implementation team to formulate and create everything from scratch for developing courses. Original versions are available and practically very helpful and there is enough information to adjust and adapt these materials for particular courses

Table 3. Specific prevention-focused courses in bachelor's programme Addictology before evaluation study (2015) and after evaluation study (2018)

\begin{tabular}{|l|l|l|}
\hline & $\begin{array}{l}\text { Before (2015) } \\
\text { Course title (hours) }\end{array}$ & $\begin{array}{l}\text { After (2018) } \\
\text { Course title (hours) }\end{array}$ \\
\hline First grade & Developmental Psychology (30) & Basics of Developmental Psychology (30) \\
\hline & Pedagogy and Special Pedagogy (30) & Introduction to Prevention of Risk Behaviours (30) \\
\hline Second grade & Primary drug prevention (30) & \\
\hline & Paediatrics (30) & Paediatrics (30) \\
\hline Third grade & & School-Based Prevention (45) \\
\hline & Working with Families (30) & Working with Families (30) \\
\hline & Tobacco Addiction: Prevention and Treatment (15) & Family-Based Prevention (45) \\
\hline & Prevention Programmes in Practice (30) & Workplace-Based Prevention (45) \\
\hline
\end{tabular}

Table 4. Prevention-focused courses in master's programme Addictology before evaluation study (2015) and after evaluation study (2018)

\begin{tabular}{|l|l|l|}
\hline & $\begin{array}{l}\text { Before (2015) } \\
\text { Course title (hours) }\end{array}$ & $\begin{array}{l}\text { After (2018) } \\
\text { Course title (hours) }\end{array}$ \\
\hline First grade & Prevention - practicum (15) & Environment-Based Prevention and Public Health Interventions (45) \\
\hline & & Media-Based Prevention and ICT (45) \\
\hline Second grade & Public Health Interventions in Practice (60) & Community-Based Prevention and Implementation Systems (45) \\
\hline & Drugs and Society (30) & Monitoring and Evaluation of Prevention Interventions and Policies (45) \\
\hline
\end{tabular}


and to ground them in the context of the entire university study programme. The trainer manuals provide guidance and backup needed for this work and provide fully transferable and practical "packages" that need minor adaptation (e.g. European examples, local programmes, some terminological changes, etc.).

\section{Different Ratio of ECTS Credits}

Despite the fact that we are talking about very technical aspects, all the changes and adaptations in terms of courses (cancelling, creating new ones, and/or joining courses together) suggest the need to rearrange the European Credit Transfer and Accumulation System (ECTS) credits in both the (BA and MA) study programmes. The original proportion (in terms of hours and ECTS credits) between the courses in terms of prevention, treatment, and harm/risk reduction in the BA and MA programmes was approximately $1: 4: 2$, which means an imbalance in the total number of hours and ECTS credits across all three dominant focuses before the implementation process - with the clear majority of hours being devoted to treatment/rehabilitation and recovery issues. After the first part of the implementation the ratio was more proportional, in a ratio of $2: 4: 2$, representing an acceptable result because of some significant overlaps (e.g. some treatment-focused courses such as Brief Interventions, Motivational Interviewing, and Counselling represent areas/courses relevant to prevention). The ECTS credits were increased after the implementation of the UPC; for the BA level it shifted from 16 to 18 credits, and for the MA level from 10 to 12 credits. The proportion corresponds to the extent of the courses (Tables 3 and 4). As mentioned above, changes in ECTS credits caused by the implementation of the UPC meant adding the requirement for both new ECTS credit schemes (for the BA and MA programmes) to be approved by the university and regulatory bodies.

\section{Course Perspective}

Both the original UPC series (implementer and co-ordinator) consist of tracks. It was therefore necessary to transform the content from the tracks to particular courses/subjects. That they had a different frame and logic model from the university study programme was evident. To mechanically adopt and transfer the content and structure of the UPC tracks to university courses/ subjects was difficult. The UPC tracks are not suitable for such a mechanical transfer. There were several critical issues influencing work on courses: prerequisites, learning outcomes, and professional competencies (for every single subject/course), the number of hours, the form of teaching and training, and the theoretical perspective. We formulated a logic model for creating structural and final course profiles according to defined competencies and learning outcomes and other critical issues - not according to the UPC tracks. Mixing or splitting the UPC tracks was very common and we used the original UPC tracks just as a source of materials. The key issue for every course was to work with learning outcomes and professional competencies and match the content to these. For example, as we based our MA programme on general principles and combining the public and mental health perspectives a long time before we integrated the UPC, this component was emphasised even more in the mixed study programme model; we linked prevention together with public health perspectives and stressed their impact not only for the addictions but for all risk behaviours.

Some UPC tracks contain theory related to more general issues and scientific areas. We deliver these issues to students through more extensive (a higher number of hours) and general subjects/ courses which we call "core or unspecific" courses. Therefore, it was not necessary to take and adapt these UPC tracks because they were already completely compatible and, in all cases, existing courses were more comprehensive. Examples of sharing non-specific courses include: Introduction to Pharmacology (32 hours), Specific Pharmacology (32 hours), Physiology (32 hours), Pathophysiology (32 hours), Anatomy (32 hours), Neurosciences (32 hours). We maintained some specific courses in our model, such as First Aid, Addiction Biology and Genetics, Social Work, Developmental Psychology, Psychopathology, Developmental Psychopathology, Psychiatry, Communication Skills, Addiction Neuroscience, or Paediatrics, because of the Czech legislation, the healthcare education of the graduates, and the perceived necessity of teaching these knowledge and skills, whether the graduate is a generic addiction professional or a prevention or treatment specialist only. This placed enormous pressure on increasing the total number of new courses and adding more hours while at the same time having control through the implementation process.

\section{Major Challenges of Implementation Process}

The theoretical perspective/framework of the Prague model (in prevention) was based on Jessor's concept of risk behaviours (22) and covered all kinds of risk behaviours (including sexual risk behaviour, bullying, violence, etc.). This specific theoretical framework required many adaptations of particular courses (examples, theory, terminology, etc.) and the trainer manuals alone were not sufficient for creating syllabuses - all the teachers had to develop new syllabuses. The by-products of these efforts proved to be a burden; some teachers were not willing/able to follow the implementation process and changes, and this resulted in a lack of enthusiasm or flexibility and motivation. The adaptation process facilitated a "generation exchange" within the teaching staff because teachers who were more versatile and could teach various courses were able to adjust their existing skills, materials, and ideas about education into a new teaching model were needed, while others were not. Besides the need for a different mindset about how to lead the students to the required graduate profile and the outcome competencies, there was also an issue of a lack of teachers with the specific background and training to enable them to teach prevention-focused courses from both theoretical and practical perspectives. These issues represented a significant strain as regards internal supervision and support for teachers.

\section{DISCUSSION}

The Czech experience with implementing the UPC into a university study programme in addiction studies that had been established for almost 15 years seems to be quite unique. Charles University, where the programme is taught, has become an International Coordinating Centre of the International Consortium of Universities for Drug Demand Reduction (ICUDDR) for Europe and this fact facilitated the idea of changing the existing 
programme and becoming more international. This experience can serve as a model for other universities in a similar situation. The ICUDDR, as a platform for bringing together universities providing education in addictions all around the world and a provider of the Universal Prevention Curriculum and Universal Treatment Curriculum, can offer and help with the implementation of the curricula in various regions, especially in Asia, Africa, and Latin America. We can see a growth in the study programme numbers every year, and yet the adaptation experience is different in comparison to the Czech Republic. The programmes are either starting from scratch at the university, or they are created and offered as non-academic education, and possibly by non-governmental organisations and institutions other than universities.

For example, in Africa, we have found universities that provide education based on the Universal Prevention and/or Universal Treatment Curricula (UPC/UTC) as members of the ICUDDR, including the University of Kibungo (Rwanda) and Makerere University (Uganda). Kenyatta University in Kenya established a new programme under the umbrella of the Colombo Plan, a postgraduate diploma in Addiction Treatment Science. Boitekanelo College in Botswana offered a five-day course in substance abuse but it is not sufficiently clear whether the UPC/UTC formed the basis for the course.

Each study programme was developed under different conditions, in various countries with different histories and situations, so it is, to a certain extent, understandable that the programmes worldwide were started and developed quite independently, without knowledge about other similar programmes $(1,2,23)$. The UPC has proved to be a great inspiration and source of many topics that are inter-related, but the results show that it is not easy to take the UPC and directly create a university study programme.

In parallel with the Prague implementation of the original UPC curriculum, an adapted European version (EUPC) was incorporated into the university context in Portugal (24). Results show that transforming the UPC into an e-learning form opened up a new perspective for students and staff in saving many hours of direct face-to-face teaching at school and saving more hours that are transferable to practically-oriented courses based on training and interactive strategies.

Every attempt to implement a new programme, no matter if it includes the UPC or not, faces some challenging situations. As Adams et al. (23) showed, there were many conditions and barriers to establishing an innovative programme in New Zealand. The authors stated that several conditions must be fulfilled for the success of the implementation process, i.e. getting support for the specialised education, legislation, etc. Another key condition is to guarantee the quality of the teaching staff who are able to flexibly adjust the way they think about education and their teaching methods. However, this may become especially difficult when facing a situation where there is a lack of qualified personnel. It is challenging to motivate and encourage young graduates to participate on clinical trainings together with experienced clinicians. Combining educators representing different age groups, with different career pathways and with different theoretical backgrounds relevant to the addiction field (that may include academics, researchers, and clinicians) has important implications for not only teaching strategies but also how to communicate with students (25). The Prague model faced changes to its structure, graduate profile, teaching methods, etc., and such a process could be seen as a challenge for some teachers. That could lead to feelings of ambivalence or even to resistance to the process. It is useful to prepare for the change and continuously reinforce its importance, and communicate about it repeatedly, transparently, and with respect to staff members' possible fears (26).

The implementation process presented here reflects changes in the long-term Czech experience and concept of a generic addiction professional. Professionals in the field have various opinions on this concept; each region works with it differently. Miovský et al. (14) defined the term 'generic' as a professional who integrates knowledge and skills from various disciplines related to addiction. The Czech graduates are able to cover topics from prevention, treatment, and social rehabilitation to harm reduction and public health interventions, and also the areas of research, drug policy, or the civil service. On the other hand, Adams et al. (23) talk about a generic professional as someone who has their initial education in some more general discipline, such as medicine, psychology, or social work, and only following higher education and specialisation can bring them the ability to work in the addiction field. Therefore, the term 'generic' in this case means education in a different, generic discipline. S. Lala Straussner, who leads the postgraduate programme "Clinical Approaches to Addiction" at New York University, talks about specialisation in addictions as only following a generic education, in this case social work (27). The question of who is a preventive professional also remains present. Should it be a separate discipline, or a part of the education in the field of addictions? Should it be a specialisation in another discipline? Is it a domain of medical doctors, teachers, or psychologists? How can the addiction specialist cover behavioural topics other than substance use risk behaviour?

Another way to look at the training of the addiction professional is through the UPC and UTC curricula, which can be attended separately, so the graduate would be a specialist only in one part of the field. We hold the opinion that prevention is an integral part of the addiction profession, and it cannot be separated. Additionally, legislation can emphasise this opinion as there must be a licensed professional in prevention so that specialised professionals can find appropriate jobs in the labour market. The important questions of a multidisciplinary approach to addictions and to education in the field still remain. It is true that multidisciplinarity brings variability in education and training (28), and yet, it seems useful when addiction specialists are able to cover different disciplines and adapt to various working contexts $(29,30)$. We observe a diversity and test new approaches and educational models, for example, a standardised model of school-based prevention qualifications that is referred to as the four-level model (31). In such a state of knowledge, we should carry out evaluation processes and try to collaborate and exchange experience. We can talk about international standards for addiction education in the future. The platforms bringing together professionals and education providers around the world (ISSUP and ICUDDR) can serve as fora where such sharing can happen.

We may also track the interesting process of defining the professional competencies of addiction workers around the world. If we go through various foreign documents defining the professional competencies of workers in addictology, we find fragmentation in the understanding of this profession. According to the specific nature of the environment, culture, and mentality, various organisations around the world have developed their 
own competency models of the addiction profession. For example, the Canadian Centre on Substance Abuse (32) published a competency model based on measurable knowledge, skills, and attitudes. They recognise that addiction workers are generally professionals from different fields and have therefore created a list of 35 items in which an addiction professional should be competent. A different view is offered by the New Zealand Ministry of Health (33). This model is very culture-specific. It recognised practical and theoretical competencies and also described the required characteristics of the addiction worker. Unlike the Canadian model, it distinguished different groups of substances and linked them with specific interventions. In the US, we can find several documents describing required competencies. The American Board of Addiction Medicine (34) operates with six key competencies consisting of knowledge and skills. The American Society of Addiction Medicine (35) defines nine competencies, which are closer to learning outcomes thanks to their connection with curricula. A very detailed document with high relevance is the competency model of the US organisation the Substance Abuse and Mental Health Service Administration (SAMHSA) (36). This competency model describes 123 competencies, which are detailed in terms of knowledge, skills, and attitudes. It is a list describing professional competencies, and yet thanks to its detailed description it may be used as a list of learning outcomes. What these documents described above have in common is their focus on treatment and counselling, working in the field, and often with a healthcare focus. If we compare the Czech study programme and the graduates' competencies with the SAMHSA (36) document, the Czech addiction worker is a very comprehensive professional with comprehensive knowledge, besides treatment, in the fields of prevention and public health, harm reduction, and methodology and a basis as a healthcare worker. This statement confirms the meaning of the usage of the competency model in preparing the new form of education for addiction specialists in the Czech Republic.

The reflection of the implementation process illustrates the potential value for existing or newly-opening university study programmes. In addition, it is important to evaluate the study programmes and ask their graduates about their satisfaction and the real impact of the knowledge and skills they have gained on their subsequent clinical practice, as it is necessary to stay up to date and, on the basis of the evaluation, to modernise the programmes and change them according to continuous reflection and progress in the field. This process then leads to an improvement in quality and, as shown in the case of the Czech study programme, keeping up with international developments in the field of specialised addiction education.

\section{CONCLUSION}

In July 2018 the Czech university programme in Addictology received accreditation from the State Authority without any requirements/limits (until 2028) and the first part of the project was successfully concluded by this formal act. On the other hand, through this process we became aware of many unexpected side effects (for the Prague team, the impact on legislation, etc.). It also divided teachers and trainers into two groups, one defending the change versus one questioning the change agents' local patriotism and attitudes towards to the original Prague curriculum. Some similar parallels we can sometimes meet in the context of terminological discussions (keeping some local/national and more or less traditionally used terms) or defending some local prevention interventions without any real evidence in terms of relevant outcomes evaluation data etc. The adaptation of the UPC had a significant impact on the study profile and competencies. Real adaptation of the UPC implies some specific unification and also emphasises an international perspective, and it is not so easy to say what is bad or good and for whom.

The university implementation opened a national discussion about the implementation of the UPC into the system of life-long education programmes and training. From September 2019, when the first group of students will attend this new model of addictology studies, we will continue evaluating how successful the process of implementation was and respond to the findings by adjusting the current state of the curriculum. The implementation necessarily requires a team of staff members with sufficient capacities who are responsible for the whole process, facilitating each step and supervising it. The role of other teachers is important - their feedback (especially if the university has its own curriculum) is critically needed for a reality check and adjusting the deficiencies. We recommend that sufficient time be made available for such preparation, as it is a time-consuming activity. Nevertheless, although we do not know yet how the programme will be run in practice, we now know that the implementation of the UPC into an existing programme with quite a long history is feasible, and can enrich the experience of the teachers and, it is hoped, future students.

\section{Conflict of Interests}

None declared

\section{Grant Support}

Institutional support was provided by Charles University, Progress Programme No. Q06/LF1, by the Grant INL/Colombo plan, and the ICUDDR.

\section{REFERENCES}

1. Pavlovská A, Miovský M, Babor TF, Gabrhelík R. Overview of the European university-based study programmes in the addictions field. Drugs (Abingdon Engl). 2017;24(6):485-91.

2. Pavlovská A, Peters RH, Gabrhelík R, Miovský M, Sloboda Z, Babor TF. Overview of the university-based addiction studies programmes in the United States. J Subst Use. 2019;24(1):55-60.

3. Bašić J. Prevention science and disability studies: a postgraduate doctoral study overview. J Public Health. 2011;19 Suppl 1:39-45.

4. McMaster University. Addiction education program closure - FAQ [Internet]. Hamilton: McMaster University [cited 2018 Jul 15]. Available from: https://www.mcmastercce.ca/addiction-education-faq.

5. Campbell ANC, Back SE, Ostroff JS, Hien DA, Gourevitch MN, Sheffer $\mathrm{CE}$, et al. Addiction research training programmes: four case studies and recommendations for evaluation. J Addict Med. 2017;11(5):333-8.

6. Forberger S, Riedel O, Bühringer G. European graduate school in addiction research: a contribution to the research education of $\mathrm{PhD} / \mathrm{MD}$ students in Europe. Drugs (Abingdon Engl). 2017;24(6):477-84

7. Messum DG, Wilkes LM, Jackson D, Peters K. Employability skills in health services management: perceptions of recent graduates. Asia Pac J Health Manag. 2016;11(1):25-32

8. Babor TF, Stenius K, Pates R, Miovský M, O’Reilly J, Candon P, editors. Publishing addiction science: a guide for the perplexed. London: Ubiquity Press; 2017. 
9. Miovský M, Vondrová A, Peters R, Kathungu B, Lososová A. National Addiction-specific Institutional Infrastructure - fundamental prerequisite for the successful implementation of specialized academic degree study programmes: a case study in historical perspective. Cent Eur J Public Health. 2019;27(Supp1.):S83-91.

10. United Nations Office on Drugs and Crime. International standards on drug use prevention, UNODC, Vienna [Internet]. UNODC; 2013 [cited $2018 \mathrm{Jul} 15]$. Available from: http://www.unodc.org/unodc/en/prevention/ prevention-standards.html.

11. European Monitoring Centre for Drugs and Drug Addiction. European drug prevention quality standards: a manual for prevention professionals. Luxembourg: Publications Office of the European Union; 2011.

12. Burkhart G. International standards in prevention: how to influence prevention systems by policy interventions? Int J Prev Treat Subst Use Disord. 2015;1(3-4):18-37.

13. Miovský M, Miller P, Grund JP, Belackova V, Gabrhelik R, Libra J. Academic education in addictology (addiction science) in the Czech Republic: analysis of the (pre-1989) historical origins. Nordisk Alkohol Nark. 2015;32(5):527-38.

14. Miovsky M, Gabrhelík R, Libra J, Popov P, Pavlovska A, Kalina K, et al. The Prague Comprehensive Model of Academic Addictology (Addiction Science) Education. Adiktologie. 2016;16(1):36-49.

15. Libra J. A „Drugs Agency“ as a possible model of a specific local antinarcotics programme. Adiktologie. 2003;3(1):70-9. (In Czech.)

16. Marsden J, Ogborne A, Farrell M, Rush B. International guidelines for the evaluation of treatment services and systems for psychoactive substance use disorders. Geneva: WHO; 2000

17. World Health Organization. Process evaluations: workbook 4. Geneva: WHO; 2000.

18. Strauss A, Corbin JM, editors. Grounded theory in practice. London: SAGE; 1997.

19. Miles MB, Huberman AM. Qualitative data analysis: an expanded sourcebook. Thousand Oaks: SAGE; 1994.

20. The Bologna Declaration [Internet]. 1999 [cited 2018 Jul 15]. Available from: http://www.magna-charta.org/resources/files/BOLOGNA DECLARATION.pdf.

21. Nantl J, Černikovský P, et al. National qualification framework of tertiary education. Part 1. National descriptors. Prague: Ministry of Education, Youth and Sports; 2010. (In Czech.)

22. Jessor R. New perspectives on adolescent risk behavior. In: Jessor R, editor. New perspectives on adolescent risk behavior. Cambridge: Cambridge University Press; 1998. p. 1-10.

23. Adams PJ, Sellman D, Newcombe D, Adamson S, White S, Deering D, et al. Postgraduate alcohol and other drug practitioner training in New Zealand: significant influences. J Stud Alcohol Drugs. 2017;78(3):468-74.

24. Henriques S, Burkhart G, Miovsky M. The first university e-learning study programme based on the adaption of the EUPC: Portuguese implementation study. Adiktologie. In press.
25. Edwards G, Babor TF, editors. Addiction and the making of professional careers. New Brunswick: Transaction Publishers; 2012.

26. Boada-Cuerva M, Boada-Grau J, Prizmic-Kuznica AJ, de-Diego NG, Vigil-Colet A. RTC-11: Adaptation of the resistance to change scale in two countries (Spain and Argentina). Anales de Psicología. 2018;34(2):360-7.

27. Straussner SLA, editor. Clinical work with substance-abusing clients. 3rd ed. New York: The Guilford Press; 2014.

28. Conley TB, Schantz DL, Shea S, Vaillancourt M. Meeting the addiction education and training needs of rural master's level social workers. Prof Dev. 2006;9(1):24-33

29. Pavlovská A, Miovský M, Vacek J. Addiction specialists in the Czech Republic: what is their place on the job market? A survey among graduates in addictology. Adiktologie. 2018;18(1):29-39.

30. Miovsky M, Kalina K, Libra J. Education in addictology in the Czech Republic: the scope and role of the proposed system. Adiktologie. 2014; 14(3):310-28.

31. Charvát M, Jurystová L, Miovský M. Four-level model of qualifications for the practitioners of the primary prevention of risk behaviour in the school system. Adiktologie. 2012;12(3):190-211.

32. Canadian Centre for Substance Abuse. Competencies for Canada's Substance Abuse Workforce: section I - behavioural competencies report [Internet]. Ottawa: CCSA; 2014 [cited 2018 Jul 15]. Available from: http:// www.ccsa.ca/Resource\%20Library/CCSA-Workforce-BehaviouralCompetencies-Report-2014-en.pdf.

33. Addiction Practitioners' Association Aotearoa-New Zealand. Addiction Intervention Competency Framework: a competency framework for professionals specialising in Problem Gambling, Alcohol and other Drug and Smoking Cessation intervention [Internet]. Wellington: dapaanz; 2011 [cited 2018 Jul 15]. Available from: http://www.dapaanz.org.nz/ $\mathrm{vdb} /$ document $/ 22$.

34. American Board of Addiction Medicine. Core competencies for addiction medicine [Internet]. ABAM; 2012 [cited 2018 Jul 15]. Available from: https://www.abam.net/become-certified/core-competencies/.

35. American Society of Addiction Medicine. The ASAM Fundamentals of Addiction Medicine Recognition Program: competencies and curriculum learning objectives [Internet]. ASAM; 2015 [cited 2018 Jul 15]. Available from: https://www.asam.org/docs/default-source/education-docs/ asam-fundamentals-recognition-program-learning-objectives-andcompetencies-final-10-1-15.pdf?sfvrsn=2.

36. Substance Abuse and Mental Health Service Administration. Addiction Counseling Competencies: the knowledge, skills, and attitudes of professional practice. Technical Assistance Publication (TAP) Series 21 [Internet]. Rockville: SAMHSA; 2006 [cited 2018 Jul 15]. Available from: https://store.samhsa.gov/system/files/sma12-4171.pdf. 